\title{
Development of Efficient Fermentation Process at Bioreactor Level by Taguchi's Orthogonal Array Methodology for Enhanced Dextransucrase Production from Weissella confusa Cab3
}

\author{
Shraddha Shukla, Arun Goyal* \\ Department of Biotechnology, Indian Institute of Technology Guwahati, Guwahati, India \\ Email: *arungoyl@iitg.ernet.in
}

Received April 20, 2012; revised May 19, 2012; accepted May 28, 2012

\begin{abstract}
The influence of medium ingredients on extracellular dextransucrase production by a new bacterial strain Weissella confusa Cab3 (Genbank Accession Number JX649223) was evaluated using fractional factorial design of Taguchi's orthogonal array. Four metabolism influencing factors viz. sucrose, yeast extract, $\mathrm{K}_{2} \mathrm{HPO}_{4}$ and Tween 80 were selected to optimize dextransucrase production by $W$. confusa Cab3 using fractional factorial design of Taguchi methodology. Based on the influence of interaction components of fermentation, least significant factors of individual level have higher interaction severity index and vice versa for enzyme production from Weissella confusa Cab3. Sucrose and yeast extract were found to be the most significant factors which positively influenced the dextransucrase production. The optimized medium composition consisted of sucrose $-5 \%$; yeast extract $-2 \% ; \mathrm{K}_{2} \mathrm{HPO}_{4}-1.0 \%$; Tween $80-0.5$, based on Taguchi orthogonal array method. The optimized composition gave an experimental value of dextransucrase activity of $17.9 \mathrm{U} / \mathrm{ml}$ at shake flask level which corresponded well with the predicted value of $17.54 \mathrm{U} / \mathrm{ml}$ by the model. The optimized medium by Taguchi method gave significant ( 3 fold) enhancement of dextransucrase activity as compared to unoptimised enzyme activity of $6.0 \mathrm{U} / \mathrm{ml}$. The dextransucrase production was scaled up in lab scale bioreactor resulting in further enhancement of enzyme activity $(22.0 \mathrm{U} / \mathrm{ml})$.
\end{abstract}

Keywords: Lactic Acid Bacteria; Weissella confusa; Dextransucrase; Taguchi’s Orthogonal Array Method; Bioreactor

\section{Introduction}

The enzymes synthesizing dextran from sucrose are known as dextransucrase (1,6- $\alpha$-d-glucan-6- $\alpha$-glucosyltransferase, EC 2.4.1.5.). They catalyze the transfer of glucosyl residues from sucrose to dextran polymer and liberate fructose [1]. Dextransucrase is produced by various Leuconostoc and Streptococcus species [2,3] and by the mold Rhizopus spp. [4]. Dextransucrase is an inducible enzyme requiring sucrose in the medium for the induction with the exception of recently isolated constitutive mutant strains viz. B-512 FMC [5], B-742 [6], B-1299 [7] and B-1355 [8]. Streptococcus species are generally constitutive and do not require sucrose in the growth media for enzyme expression [9]. The dextransucrase is a large protein consisting of approximately 1600 amino acid sequence [10]. Schematic structure of dextransucrases for which encoding genes have been cloned suggests that dextransucrase consists of A, signal peptide;

"Corresponding author.
$\mathrm{B}$, variable region; $\mathrm{C}, \mathrm{N}$-terminal catalytic domain; $\mathrm{D}$, C-terminal glucan binding domain. $\mathrm{N}$ terminal part contains typical signal peptides of Gram-positive bacteria [11]. The main characteristic of the structure of glucansucrase signal peptides is that it is well conserved [11]. N terminal signal peptide aids in the translocation of dextransucrase across bacterial membrane. The non-conserved region located just downstream of the signal peptide tends to have no important role in the enzyme mechanism. Its deletion does not affect the enzyme activity [12]. As shown by protein sequence alignments of different dextransucrases, the $\mathrm{N}$-terminal domain is highly conserved and was catalytic domain [13]. The $\mathrm{C}$-terminal domain is a functional glucan binding domain and consists of a series of direct repeating units [10]. Dextransucrase catalyses dextran biosynthesis by transferring glucosyl residues coming from sucrose cleavage enzymes and are of high-molecular-mass $\left(10^{7}\right.$ to $\left.10^{8} \mathrm{Da}\right)$. The dextran synthesis reaction occurs by successive transfer of glucosyl units to the polymer. Dextran is 
composed of a linear chain of glucosyl residues linked through $\alpha(1 \rightarrow 6)$ glucosidic bonds and several $\alpha(1 \rightarrow 2)$, $\alpha(1 \rightarrow 3)$, or $\alpha(1 \rightarrow 4)$ branched linkages. Dextrans are useful in various industries because of their inertness, porous structure and gelling properties [14]. These are used as food syrup stabilizers, matrix of chromatography columns, blood plasma substitutes, antithrombogenic agents, treatment for iron deficiency anaemia, drug carriers $[14,15]$.

Microorganisms utilize various substrates as nutrient source to avail their growth and metabolic activities. By utilizing the nutrients microorganisms subsequently produce various metabolism-related products. However, fine-tuning of nutrient concentrations is an essential aim to regulate the microbial metabolism and associated metabolic product production. For the fine tuning of the optimization of responses, there are various methods reported in the literature like Box Behnken method, CCD method, neural networking and Taguchi's orthogonal array based methodology. Singh et al., 2008 [16] used artificial intelligence based optimization method for enhancement of exocellular glucansucrase production from Leuconostoc dextranicum NRRL B-1146. Purama and Goyal, 2008 [17] employed response surface methodology for maximizing dextransucrase production from Leuconostoc mesenteroides NRRL B-640 in a bioreactor. Recently Patel et al., 2011 [18] optimized the medium component for a new isolate Pediococcus pentosaceus (SPAm) using response surface methodology.

Taguchi's orthogonal methodology appends planning of the experiments, their conductivity and finally evaluation of the results of matrix experiments to find out the best level of the factors for the optimization process. In this method the best levels of the factors maximize the Signal-to-Noise ratios which are log functions of desired output characteristics. Weissella confusa is a lactic acid bacterial strain which produces dextransucrase. There are very few reports where the dextran production capacity of this strain have been explored. However Weissella confusa is a very potent candidate for dextran production in the sense that it has high dextran yield and the dextran produced by this strain is more linear in nature thus finds its place in food industries. In our earlier reports, the dextransucrase and dextran production capacity by a fermented cabbage isolate Weissella confusa $\mathrm{Cab} 3$ were studied [19]. Weissella confusa Cab3 produced dextransucrase $(6.0 \mathrm{U} / \mathrm{ml})$ in medium described by Tsuchiya et al., 1952. Further the effects of various carbon sources, nitrogen sources and buffering agents were investigated for their effects on dextransucrase and dextran production from Weissella confusa Cab3 [20]. In the present study the medium components were optimized for the enhanced dextransucrase production by Weissella confusa Cab3 using Taguchi's orthogonal method. Subse- quently, the dextransucrase production by this strain was scaled up to lab scale bioreactor using the statistically designed medium. As of my knowledge this is the first report of enhancement of the dextransucrase activity by Weissella confusa using statistically methods.

\section{Materials and Methods}

\subsection{Microorganism, Maintenance and Preparation of Seed Culture}

The bacterial strain Weissella confusa Cab3 (Genbank Accession Number JX649223) isolated from fermented cabbage [19] was used for optimization of medium composition for dextransucrase production. The organism was maintained in MRS medium [21] stabs incubated at $25^{\circ} \mathrm{C}$, stored at $4^{\circ} \mathrm{C}$ and subcultured every two weeks. Fermentation experiments were carried out using Weissella confusa Cab3, subcultured and grown (12 - 14 $\mathrm{h}$ old) in medium described by Tsuchiya et al., 1952 [22] at optimised culture conditions i.e. $25^{\circ} \mathrm{C}$ and $180 \mathrm{rpm}$ [19]. The $\mathrm{pH}$ of the medium was adjusted to 7.0 using $2 \mathrm{M} \mathrm{HCl}$ solution.

\subsection{Production of Dextransucrase}

The production of dextransucrase was carried out in 250 $\mathrm{ml}$ Erlenmeyer flasks containing $100 \mathrm{ml}$ medium as per the design inoculated with $1 \%$ culture inoculum. The inoculated flasks were incubated under orbital shaking at $180 \mathrm{rpm}$ and $25^{\circ} \mathrm{C}$ for $12-15 \mathrm{~h}$. The samples $(1 \mathrm{ml})$ were withdrawn at indicated time intervals and centrifuged at $8000 \mathrm{~g}$ for $10 \mathrm{~min}$ at $4^{\circ} \mathrm{C}$ to separate the cells. The cell free supernatant was analyzed for enzyme activity.

\subsection{Dextransucrase Activity Assay}

The enzyme assay was carried out in $1 \mathrm{ml}$ reaction mixture containing $5 \%(\mathrm{w} / \mathrm{v})$ sucrose, $20 \mathrm{mM}$ sodium acetate buffer (pH 5.4) and $20 \mu \mathrm{l}$ cell free supernatant. The enzymatic reaction was performed at $30^{\circ} \mathrm{C}$ for $15 \mathrm{~min} .100$ $\mu \mathrm{l}$ aliquot from the reaction mixture was taken for reducing sugar estimation. The enzyme activity was determined by estimating the released reducing sugar by Nelson, 1944 [23] and Somogyi, 1945 [24] method. The absorbance of the color developed was measured by spectrophotometer (Varian, Carry 100) at $500 \mathrm{~nm}$. Fructose was used to plot the standard graph.

\subsection{Taguchi Methodology}

An L16 orthogonal array in four levels was used consisting of 16 different experimental trials for the medium optimization for dextransucrase production by Weissella confusa Cab3. The design for the L16 OA was developed and analyzed using "MINITAB 15" software. All four 
selected factors, their assigned levels and the experimental design along with dextransucrase production data are listed in Tables $\mathbf{1}$ and 2, respectively. To achieve the maximum dextransucrase production by Weissella confusa Cab3, sucrose $(\%, \mathrm{w} / \mathrm{v})$, Yeast extract $(\%, \mathrm{w} / \mathrm{v})$, dipotassium hydrogen orthophosphate $\left(\mathrm{K}_{2} \mathrm{HPO}_{4} ; \%\right.$, w/v) and Tween $80(\%, v / v)$ were selected for medium optimization for enhanced dextransucrase production because they had significant impact on dextransucrase production as screened in our earlier findings [20]. Sucrose was the most effective medium component for dextransucrase production. However yeast extract, $\mathrm{K}_{2} \mathrm{HPO}_{4}$, and Tween80, displayed moderate effect on dextransucrase production from Weissella confusa Cab3. Experimental results were fitted in Taguchi software to analyze further for predicted values, individual and interactive influences, ANOVA, optimum conditions and to know the contribution of each selected fermentation factor in the production of dextransucrase by this bacterial strain. Validation experiments were performed using optimized parameters of fermentation medium components and levels by software. The dextransucrase production medium was validated at shake flask level. The optimized medium for dextransucrase production from Weissella confusa Cab3 were inoculated with $1 \%$ of fresh seed culture of Weissella confusa Cab3 and various fermentation parameters like optical density of cell $\left(\mathrm{OD}_{600}\right)$, enzyme activity, protein concentration [25], and sucrose concentration were determined.

The dextransucrase production using optimized medium was scaled up in 1L volume of culture medium in a 3L bioreactor (Applikon, model Bio Console ADI 1025).
The bioreactor is equipped with $\mathrm{pH}$ probe, oxygen probe, foam sensor, and stirrer of two-six bladed Rushton turbines. For controlled $\mathrm{pH}$ cultivations, the $\mathrm{pH}$ was maintained at 7.0 by addition of $2 \mathrm{M} \mathrm{NaOH}$ and $2 \mathrm{M} \mathrm{HCl}$ solution. During the experiments, temperature and aeration rate were controlled at $25^{\circ} \mathrm{C}$ and $2 \mathrm{vv}^{-1} \mathrm{~min}^{-1}$, respectively. The Dissolved Oxygen (DO) was calibrated to $100 \%$ before inoculation. The initial agitation rate was set to $200 \mathrm{rpm}$ and it was changed accordingly to maintain the DO above 30\%. 1\% inoculum from $12 \mathrm{~h}$ grown culture was inoculated in the bioreactor. The parameters like dextransucrase activity, sucrose concentration, cell optical density and dry cell weight were analyzed at regular interval. The cell optical density was taken at 600 $\mathrm{nm}$. The sucrose concentration was determined by estimating the reducing sugars by the method of Sumner and Sisler (1944) [26]. Sterile Soybean oil was simultaneously employed as anti-foam agent.

\section{Results and Discussion}

The optimum temperature, $\mathrm{pH}$ and shaking condition

Table 1. Selected factors and their assigned levels for dextransucrase production by Weissella confusa Cab3.

\begin{tabular}{ccccc}
\hline Factor & Level 1 & Level 2 & Level 3 & Level 4 \\
\hline Sucrose (\%, w/v) & 2 & 3 & 4 & 5 \\
Yeast extract (\%, w/v) & 0.1 & 0.5 & 1.0 & 2.0 \\
$\mathrm{~K}_{2} \mathrm{HPO}_{4}(\%, \mathrm{w} / \mathrm{v})$ & 0.1 & 0.5 & 1.0 & 2.0 \\
Tween80 $(\%, \mathrm{v} / \mathrm{v})$ & 0.01 & 0.1 & 0.5 & 1.0 \\
\hline
\end{tabular}

Table 2. Fractional factorial design of L-16 orthogonal array used for dextransucrase production optimization by Weissella confusa Cab3.

\begin{tabular}{|c|c|c|c|c|c|c|}
\hline S. No. & Sucrose & YEP & $\mathrm{K}_{2} \mathrm{HPO}_{4}$ & T80 & $\mathbf{U} / \mathbf{m l}$ & FITS (U/ml) \\
\hline 1 & 2.0 & 0.1 & 0.1 & 0.01 & 1.60 & 1.19 \\
\hline 2 & 2.0 & 0.5 & 0.5 & 0.1 & 1.67 & 0.85 \\
\hline 3 & 2.0 & 1.0 & 1.0 & 0.5 & 2.87 & 3.37 \\
\hline 4 & 2.0 & 2.0 & 2.0 & 1.0 & 4.00 & 4.73 \\
\hline 5 & 3.0 & 0.1 & 0.5 & 0.5 & 5.80 & 6.53 \\
\hline 6 & 3.0 & 0.5 & 0.1 & 1.0 & 3.99 & 4.49 \\
\hline 7 & 3.0 & 1.0 & 2.0 & 0.01 & 4.60 & 3.78 \\
\hline 8 & 3.0 & 2.0 & 1.0 & 0.1 & 6.68 & 6.26 \\
\hline 9 & 4.0 & 0.1 & 1.0 & 1.0 & 12.00 & 11.18 \\
\hline 10 & 4.0 & 0.5 & 2.0 & 0.5 & 10.42 & 10.01 \\
\hline 11 & 4.0 & 1.0 & 0.1 & 0.1 & 6.40 & 7.13 \\
\hline 12 & 4.0 & 2.0 & 0.5 & 0.01 & 11.29 & 11.79 \\
\hline 13 & 5.0 & 0.1 & 2.0 & 0.1 & 11.85 & 12.35 \\
\hline 14 & 5.0 & 0.5 & 1.0 & 0.01 & 12.87 & 13.61 \\
\hline 15 & 5.0 & 1.0 & 0.5 & 1.0 & 14.96 & 14.55 \\
\hline 16 & 5.0 & 2.0 & 0.1 & 0.5 & 17.00 & 16.18 \\
\hline
\end{tabular}


were $25^{\circ} \mathrm{C}, 7.0$ and $180 \mathrm{rpm}$, respectively for dextransucrase production from Weissella confusa Cab3 as reported earlier [19]. Weissella confusa Cab3 grew well within the range of $\mathrm{pH} 5.0$ to 7.0 , and temperature $20^{\circ} \mathrm{C}$ to $45^{\circ} \mathrm{C}$ however Weissella confusa $\mathrm{Cab} 3$ produced maximum dextransucrase $(6.0 \mathrm{U} / \mathrm{ml})$ at $\mathrm{pH} 7.0$ and $25^{\circ} \mathrm{C}$ in the enzyme production medium [19]. As reported earlier, the effects of several medium components were investigated and sucrose, Tween80, yeast extract and $\mathrm{K}_{2} \mathrm{HPO}_{4}$ were effective nutrients which displayed higher dextransucrase production [20]. Based on the earlier results, L-16 Taguchi's orthogonal array method was designed, where the factors were varied in four levels for determining optimal medium components for dextransucrase production from Weissella confusa Cab3. Level 1 for each factor was fixed at negative side, considering the factors' role in dextransucrase production whereas, level 2 and 3 were considered as intermediate level for the production of dextransucrase. Level 4 of each factor was selected at relatively higher concentration range. Table $\mathbf{1}$ indicates the selected fermentation factors and their levels for optimization of dextransucrase production by this bacterial strain. The design matrix and dextransucrase production data are represented in Table 2. A little variation was noted between software-predicted and experimental values in dextransucrase production. The dextransucrase production by Weissella confusa Cab3 varied
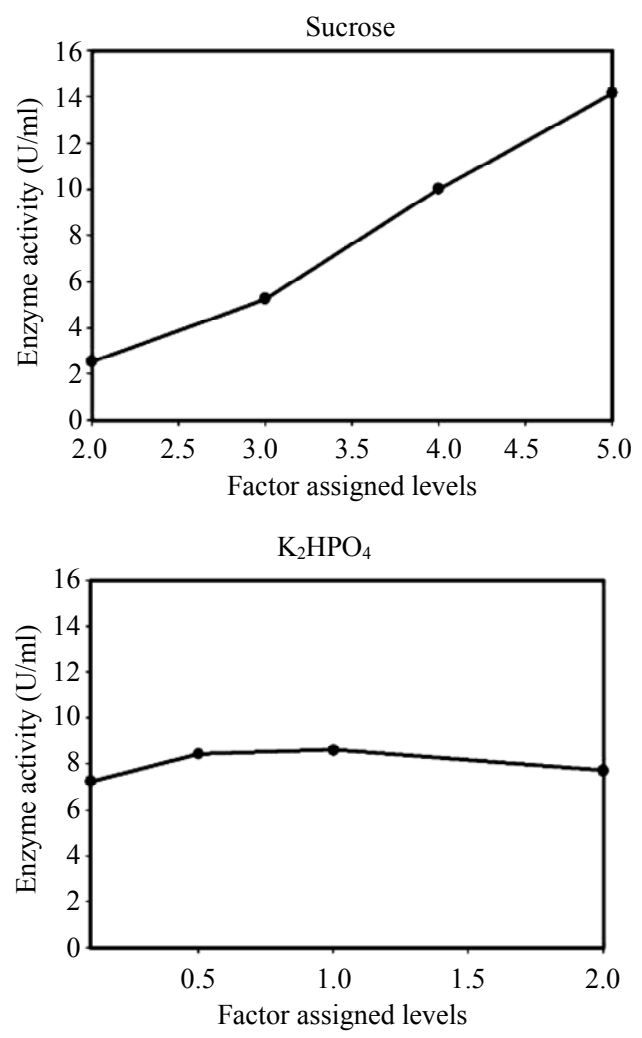

widely from $1.6-17.0 \mathrm{U} / \mathrm{ml}$. The variation in dextransucrase production is shown in Figure 1 and Table 2.

The difference between average value of each factor at higher level and lower level indicated the relative influence of the effect at their individual capacities. The order in which the individual components selected in the present study affected the dextransucrase production can be ranked as sucrose $>$ yeast extract $>$ Tween $80>\mathrm{K}_{2} \mathrm{HPO}_{4}$, suggesting that sucrose, yeast extract and Tween 80 had substantial effect and $\mathrm{K}_{2} \mathrm{HPO}_{4}$ had least effect on dextransucrase production by Weissella confusa (Table 3 ). Highest delta value of sucrose (11.635) reflected it to be most significant factor for the dextransucrase production. As the concentration was increased to $5 \%$ (level 4), maximum dextransucrase production occurred. Yeast extract and Tween 80 were the next important nutrients for dextransucrase production, $2 \%(\mathrm{w} / \mathrm{v})$ and $0.5 \%(\mathrm{v} / \mathrm{v})$ being optimum for dextransucrase production. The significance of each factor on dextransucrase production can be seen from the corresponding $\mathrm{t}$ and $\mathrm{P}$ values listed in Table 4. The ANOVA table demonstrates that the sucrose was the significant factor for the dextransucrase production, as is evident from the Fisher's F-test with a very low probability value $(\mathrm{p}>\mathrm{F})=0.005$ (Table 4$)$. Table 5 represents the optimum conditions required for the production of maximum dextransucrase production. The experimental data revealed that selected level 4
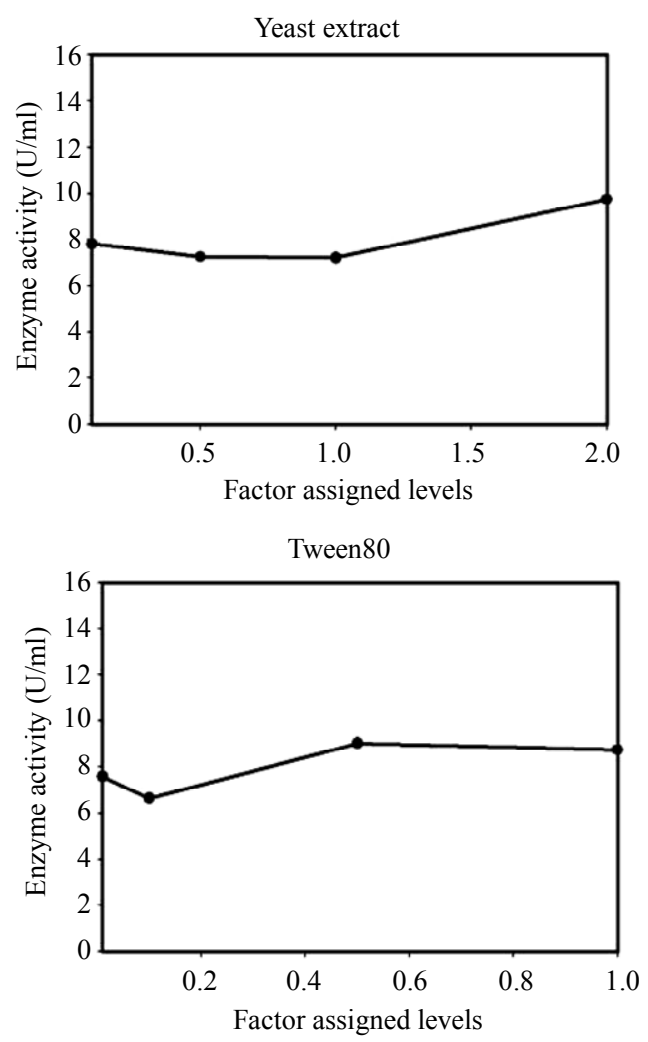

Figure 1. Multiple graphs of main effects on dextransucrase production by Weissella confusa Cab3. 
Table 3. Impact of fermentation factors and their assigned levels on dextransucrase production by Weissella confusa Cab3.

\begin{tabular}{lcccccc}
\hline Factor & Level 1 & Level 2 & Level 3 & Level 4 & Delta & Rank \\
\hline Sucrose & 2.536 & 5.267 & 10.028 & 14.172 & 11.635 & 1 \\
Yeast extract & 7.814 & 7.239 & 7.208 & 9.742 & 2.534 & 2 \\
K$_{2} \mathbf{H P O}_{4}$ & 7.248 & 8.431 & 8.605 & 7.718 & 1.358 & 4 \\
Tween80 & 7.592 & 6.649 & 9.024 & 8.738 & 2.375 & 3 \\
\hline
\end{tabular}

Table 4. Analysis of variance of experimental data on dextransucrase production by Weissella confusa Cab3.

\begin{tabular}{lccccc}
\hline Factors & DF & \multicolumn{1}{c}{ SS } & MS & F-value & Prob. (P) > F \\
\hline Sucrose & 3 & 318.095 & 106.032 & 48.88 & 0.005 \\
Yeast extract & 3 & 17.107 & 5.702 & 2.63 & 0.224 \\
K $_{\mathbf{2}} \mathbf{H P O}_{4}$ & 3 & 4.790 & 1.597 & 0.74 & 0.596 \\
Tween80 & 3 & 14.338 & 4.779 & 2.20 & 0.267 \\
Residual error & 3 & 6.507 & 2.169 & & \\
Others & 15 & 360.837 & & & \\
\hline
\end{tabular}

Table 5. Optimum conditions and levels of factors.

\begin{tabular}{lcc}
\hline \multicolumn{1}{c}{ Factor } & Optimum Concentration & Level \\
\hline Sucrose $(\% \mathrm{w} / \mathrm{v})$ & 5 & 4 \\
Yeast extract $(\% \mathrm{w} / \mathrm{v})$ & 2.0 & 4 \\
$\mathrm{~K}_{2} \mathrm{HPO}_{4}(\% \mathrm{w} / \mathrm{v})$ & 1.0 & 3 \\
Tween $80(\% \mathrm{v} / \mathrm{v})$ & 0.5 & 3 \\
\hline
\end{tabular}

value of sucrose and yeast extract of the medium were observed to be optimum for dextransucrase production, whereas for $\mathrm{K}_{2} \mathrm{HPO}_{4}$ and Tween 80 , selected level 3 values, were observed to be good for optimal enzyme production. The model was highly significant considering to its $99.1 \% \mathrm{R}^{2}$ value.

Taguchi's orthogonal methodology predicted the maximum dextransucrase production of $17.54 \mathrm{U} / \mathrm{ml}$, in a medium containing $(\mathrm{g} / \mathrm{L})$ sucrose, $50.0 ; \mathrm{K}_{2} \mathrm{HPO}_{4}, 10$; yeast extract, 2.0; Tween $80,5(\mathrm{ml} / \mathrm{L}) ; \mathrm{MgSO}_{4} \cdot 7 \mathrm{H}_{2} \mathrm{O}, 0.2$; $\mathrm{MnSO}_{4} \cdot 4 \mathrm{H}_{2} \mathrm{O}, 0.01 ; \mathrm{FeSO}_{4} \cdot 7 \mathrm{H}_{2} \mathrm{O}, 0.01 ; \mathrm{CaCl}_{2} \cdot 2 \mathrm{H}_{2} \mathrm{O}$, 0.01 and $\mathrm{NaCl} 0.01$. The dextransucrase production using statistically optimized medium was validated at shake flask level and scaled up in a 31 lab scale bioreactor using 11 of statistically designed medium. The fermentation profile of dextransucrase production from Weissella confusa $\mathrm{Cab} 3$ at shake flask and bioreactor level is shown in Figures 2(a) and (b), respectively. Table 6 shows comparison of maximum attained fermentation parameters using unoptimised medium and optimized medium from Weissella confusa Cab3. For the bioreactor the online data such as dissolved oxygen, $\mathrm{pH}$, temperature and agitation were monitored and the offline data like enzyme activity, sucrose concentration and cell optical density were plotted with time (Figure 2(b)). The enzyme activity and the cell optical density reached maximum at $10-12 \mathrm{~h}$ of fermentation at both shake flask and bioreactor level. The experimentally calculated maximum dextransucrase activity at shake flask level was $17.9 \mathrm{U} / \mathrm{ml}$ which was in agreement with the predicted values. The increase in dextransucrase activity of the Weissella confusa Cab3 after medium optimization (17.9 $\mathrm{U} / \mathrm{ml}$ ) was about 3.0 fold higher as compared to unoptimized medium $(6.0 \mathrm{U} / \mathrm{ml})$. The dextransucrase activity at bioreactor level after $10-12 \mathrm{~h}$ was $22.0 \mathrm{U} / \mathrm{ml}$ (3.5 U/mg) which was more than that observed at shake flask level using the optimized medium (Table 6). Oxygen is known to have positive effects on the growth of certain strains of L. mesenteroides [27]. Thus the higher production of dextransucrase in bioreactor as compared to flask culture is possibly be due to the effect of oxygen mass transfer rates on biosynthesis of dextransucrase. In both the cases (shake flask and bioreactor level) sucrose concentration profiles showed maximum consumption of sucrose during first $10-15 \mathrm{~h}$, with the maximum production of dextransucrase using the optimized medium. The dextransucrase production $(22.0 \mathrm{U} / \mathrm{ml}, 3.5 \mathrm{U} / \mathrm{mg})$ using statistically optimized medium by Weissella confusa $\mathrm{Cab3}$ at lab scale bioreactor level is higher than that observed with other lactic acid strains in their respective optimized medium. There is no literature available about the optimization of medium composition for dextransucrase production from Weissella confusa. Leuconostoc mesenteroides NRRL B-640 produced $10.7 \mathrm{U} / \mathrm{ml}$ dextransucrase activity in the optimised medium [17]. However according to a recent study by Patel et al., 2011 [18] a mutant Pediococcus pentosaceus (SPAm) showed substantially higher dextransucrase activity $(15.6 \mathrm{U} / \mathrm{ml})$. A Leuconostoc mesenteroides strain isolated from idli batter, an Indian fermented food was used for the optimisation for enhanced dextransucrase yield using response surface methodology [28]. After optimization 489.12 $\mathrm{DSU} / \mathrm{ml}(23.8 \mathrm{U} / \mathrm{ml})$ activity was reported which was 5.5 fold higher than that in basic medium, however, they used very high concentration of sucrose $(13.75 \%, \mathrm{w} / \mathrm{v})$. In contrast to their findings, in present study lesser concentration of sucrose $(5.0 \%, \mathrm{w} / \mathrm{v})$ was used which resulted in substantial high dextransucrase production.

\section{Conclusion}

Dextransucrase activity of Weissella confusa Cab3 was 

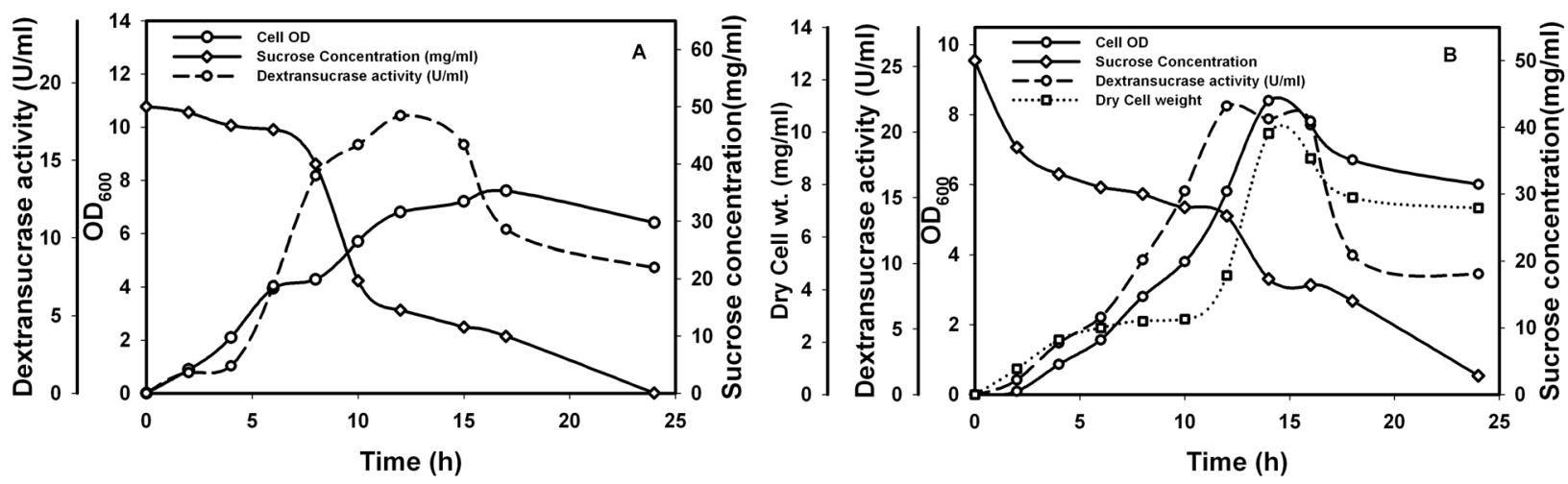

Figure 2. Fermentation profile of Weissella confusa Cab3 using statistically designed medium for dextransucrase production. The cell growth, dry cell weight, dextransucrase production and sucrose concentration changes are shown at: (A) Shake flask; (B) Lab scale bioreactor level.

Table 6. Comparison of fermentation parameters for dextransucrase production using unoptimized and optimised medium from Weissella confusa Cab3.

\begin{tabular}{|c|c|c|c|c|}
\hline \multicolumn{5}{|c|}{ Tsuchiya medium (18) } \\
\hline Levels & Enzyme activity $(\mathrm{U} / \mathrm{ml})$ & Specific activity (U/mg) & Cell OD 600 & Dry cell wt $(\mathrm{mg} / \mathrm{ml})$ \\
\hline Shake Flask (100 ml) & 6.0 & 1.0 & 5.4 & 4.1 \\
\hline \multicolumn{5}{|c|}{ Optimized medium for dextransucrase production } \\
\hline Shake Flask (100 ml) & 17.9 & 3.0 & 7.6 & 7.1 \\
\hline Bioreactor (1000 ml) & 22.0 & 3.5 & 8.4 & 9.9 \\
\hline
\end{tabular}

$6.0 \mathrm{U} / \mathrm{ml}$ with unoptimized medium. Using statistical methods the medium composition for Weissella confusa Cab3 was optimized. The optimization by Taguchi's Orthogonal array method gave optimized medium consisting of $5.0 \%$ sucrose; $2.0 \%$ yeast extract; $1.0 \% \mathrm{~K}_{2} \mathrm{HPO}_{4}$ and $0.5 \%$ Tween 80 resulting in enhanced dextransucrase production. The predicted value of dextransucrase (17.54 $\mathrm{U} / \mathrm{ml}$ ) was in good agreement with the experimental values from shake flask culture $(17.9 \mathrm{U} / \mathrm{ml})$. After scaling up the dextransucrase production in a lab scale bioreactor $22.0 \mathrm{U} / \mathrm{ml}$ enzyme activity was obtained. The optimized medium gave 3.0 and 3.7 fold higher dextransucrase production at shake flask and bioreactor level, respectively from Weissella confusa Cab3 as compared to unoptimized medium. This research article is first effort to understand the effects of various medium components on Weissella confusa Cab3, which is very potent microorganism for the production of dextransucrase at industrial level.

\section{Acknowledgements}

The research work was financially supported by a project grant from an Indo-Finland joint project, Department of Biotechnology, Ministry of Science and Technology, New Delhi, India to AG.

\section{REFERENCES}

[1] E. J. Hehre, "Enzymatic Synthesis of Polysaccharides: A Biological Type of Polymerization," Advances in Enzymology, Vol. 11, 1951, pp. 297-337.

[2] V. Monchois, R. M. Willemot and P. Monsan, "Glucansucrases: Mechanism of Action and Structure-Function Relationships," FEMS Microbiology Reviews, Vol. 23, No. 2, 1999, pp. 131-151.

doi:10.1111/j.1574-6976.1999.tb00394.x

[3] P. Monsan, S. Bozonnet, C. Albenne, G. Joucla, R. M. Willemot and M. Remaund-Simeon, "Homopolysaccharides from Lactic Acid Bacteria," International Dairy Journal, Vol. 11, 2001, pp. 675-685. doi:10.1016/S0958-6946(01)00113-3

[4] N. V. Sankpal, A. P. Joshi, S. R. Sainkar and B. D. Kulkarni, "Production of Dextran by Rhizopus sp. Immobilized on Porous Cellulose Support," Process Biochemistry, Vol. 37, No. 4, 2001, pp. 395-403. doi:10.1016/S0032-9592(01)00221-7

[5] M. Kitaoka and J. F. Robyt, "Large-Scale Preparation of Highly Purified Dextrasucrase from a High Producing Constitutive Mutant of Leuconostoc mesenteroides B512FMC," Enzyme and Microbial Technology, Vol. 23, No. 6, 1998, pp. 386-391. doi:10.1016/S0141-0229(98)00060-X

[6] D. Kim and J. F. Robyt, "Production, Selection, and 
Characteristics of Mutants of Leuconostoc mesenteroides B-742 Constitutive for Dextransucrases," Enzyme and Microbial Technology, Vol. 17, No. 8, 1995, pp. 689-695. doi:10.1016/0141-0229(94)00021-I

[7] D. Kim and J. F. Robyt, "Dextransucrase Constitutive Mutans of Leuconostoc mesenteroides B-1299," Enzyme and Microbial Technology, Vol. 17, No. 12, 1995, pp. 1050-1056. doi:10.1016/0141-0229(95)00039-9

[8] G. L. Cote, J. A. Ahlgren and M. R. Smith, "Some Structural Features of an Insoluble D-Glucan from a Mutant Strain of Leuconostoc mesenteroides NRRL B-1355," Journal of Industrial Microbiology and Biotechnology, Vol. 23, No. 1, 1999, pp. 656-660. doi:10.1038/sj.jim.2900678

[9] H. Eifuku, A. Yoshimitsu-Narita, S. Sato, T. Yakushiji and M. Inoue, "Production and Partial Characterization of the Extracellular Polysaccharides from Oral Streptococcus salivarius," Carbohydrate Research, Vol. 194, 1989, pp. 247-260. doi:10.1016/0008-6215(89)85023-2

[10] V. Monchois, R.-M. Willemot and P. Monsan, "Glucansucrases: Mechanism of Action and Structure-Function Relationships," FEMS Microbiology Reviews, Vol. 23, No. 2, 1999, pp. 131-151. doi:10.1111/j.1574-6976.1999.tb00394.x

[11] V. Monchois, P. R.-S. Monsan and R. M. Willemot, "Cloning and Sequencing of an Extracellular Dextransucrase (DSRB) from Leuconostoc mesenteroides NRRL B-1299 Synthesizing Only $\alpha(1-6)$ Glucan," FEMS Microbiology Letters, Vol. 159, No. 2, 1998, pp. 307-315. doi:10.1111/j.1574-6968.1998.tb12876.x

[12] H. Abo, T. Matsumura, T. Kodama, H. Ohta, K. Fukui, K. Kato and H. Kagawa, "Peptide Sequences for Sucrose Splitting and Glucan Binding within Streptococcus sobrinus Glucosyltransferase (Water-Insoluble Glucan Synthetase)," Journal of Bacteriolology, Vol. 173, 1991, pp. 989-996.

[13] J. J. Ferretti, M. L. Gilpin and R. R. B. Russell, "Nucleotide Sequence of a Glucosyltransferase Gene from Streptococcus sobrinus Mfe28," Journal of Bacteriology, Vol. 169, 1987, pp. 4271-4278.

[14] S. Patel, A. Majumder and A. Goyal, "Potentials of exopolysaccharides from Lactic Acid Bacteria," Indian Journal of Microbiology, Vol. 52, No. 1, 2012, pp. 3-12. doi:10.1007/s12088-011-0148-8

[15] R. K. Purama, A. Goyal, "Dextransucrase Production by Leuconostoc mesenteroides," Indian Journal of Microbiology, Vol. 2, 2005, pp. 89-101.

[16] A. Singh, A. Majumder and A. Goyal, "Artificial Intelligence Based Optimization of Exocellular Glucansucrase Production from Leuconostoc dextranicum NRRL B1146," Bioresource Technology, Vol. 99, No. 17, 2008, pp. 8201-8206. doi:10.1016/j.biortech.2008.03.038

[17] R. K. Purama and A. Goyal, "Screening and Optimization of Nutritional Factors for Higher Dextransucrase Production by Leuconostoc mesenteroides NRRL B-640 Using Statistical Approach," Bioresource Technology, Vol. 99, No. 15, 2008, pp. 7108-7114.

doi:10.1016/j.biortech.2008.01.032

[18] S. Patel, D. Kothari and A. Goyal, "Enhancement of Dextransucrase Activity of Pediococcus pentosaceus Mutant SPAm1 by Response Surface Methodology," Indian Journal of Microbiology, Vol. 10, 2011, pp. 346-351.

[19] S. Shukla and A. Goyal, "16S rRNA Based Identification of a Glucan Hyper-Producing Weissella confuse," Enzyme Research, 2011, Article ID: 250842.

[20] S. Shukla and A. Goyal, "Optimization of Fermentation Medium for Enhanced Glucansucrase and Glucan Production from Weissella confusa," Brazilian Archives of Biology and Technology, Vol. 54, No. 6, 2011, pp. 1117 1124.

[21] J. C. De Man, M. Rogosa and M. E. Sharpe, "A Medium for the Cultivation of lactobacilli," Journal of Applied Bacteriology, Vol. 23, No. 1, 1960, pp. 130-135. doi:10.1111/j.1365-2672.1960.tb00188.x

[22] H. M. Tsuchiya, H. J. Koepsell, J. Corman, G. Bryant, M. O. Bogard, V. H. Feger and R. W. Jackson, "The Effect of Certain Culture Factors on Production on Dextransucrase by Leuconostoc mesenteroides," Journal of Bacteriology, Vol. 64, 1952, pp. 521-526.

[23] N. Nelson, "A Photometric Adaptation of the Somoyogi Method for the Determination of Glucose," Journal of Biological Chemistry, Vol. 153, 1944, pp. 375-380.

[24] M. Somogyi, "A New Reagent for the Determination of Sugars," Journal of Biological Chemistry, Vol. 160, 1945 , pp. 61-68.

[25] O. H. Lowry, N. J. Rosebrough, A. L. Farr and R. J. Randall, "Protein Measurement with the Folin Phenol Reagent," Journal of Biological Chemistry, Vol. 193, 1951, pp. 265-275.

[26] J. B. Sumner and E. B. Sisler, "A Simple Method for Blood Sugar," Archives of Biochemistry, Vol. 4, 1944, pp. 333-336.

[27] V. B. Veljkovic, M. L. Lazic, D. J. Rutic, S. M. Jovanovic and D. U. Skala, "Effect of Aeration on Extracellular Dextran Production by Leuconostoc mesenteroides," Enzyme and Microbial Technology, Vol. 14, No. 8, 1992, pp. 665-668. doi:10.1016/0141-0229(92)90044-O

[28] S. D. Sawale and S. S. Lele, "Increased Dextransucrase Production by Response Surface Methodology from $\mathrm{Leu}$ conostoc Species; Isolated from Fermented Idli Batter," Global Journal of Biotechnology and Biochemistry, Vol. 4, No. 2, 2009, pp. 160-167. 